\title{
A Validated and Applicable Direct Injection LC/MS/MS Method of Fourteen Drugs of Abuse in Urine Samples to Avoid the False Positive/Negative Results of Immunoassay Techniques in Forensic Cases
}

\author{
T. Mahdy I,*, A. A. Al-Sulaiti', Y. Abdelaziz', A. Fikry', G.M. Hagl, and Mohammad I. Ahmad ${ }^{2, *}$

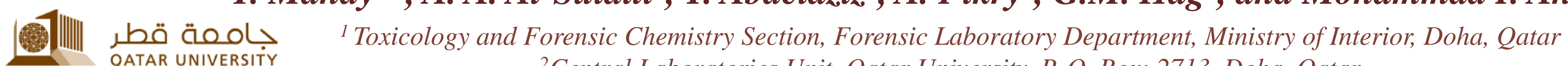 \\ ${ }^{2}$ Central Laboratories Unit, Qatar University, P. O. Box: 2713, Doha, Qatar
}

Correspondence:*thamed@moi.gov.qa; Mohammad.Ibrahim@qu.edu.qa

\section{ABSTRACT}

Many false positive and false negative results have been detected in immunoassay analyses of drugs of abuse in urine samples. A method of direct injection of diluted urine into LC/MS/MS was developed and validated for detection and quantitation of Amphetamine, Methamphetamine, MDMA, MDA, Benzoylecgonine, Ecgonine, Norpseudoephedrine, Ephedrine, Tapentadol, Tramadol, O-desmethyltramadol, Tapentadol, Pregabline, Gabapentine and Methadone to avoid the false positive and false negative results in urine samples. Linearity of Amphetamine, Methamphetamine MDMA, MDA, Benzoylecgonine, Ecgonine, Norpseudoephedrine and Ephedrine was $(60-2400 \mathrm{ng} / \mathrm{mL})$, for Tapentadol, Tramadol, Odesmethyltramadol, and Methadone was (50-1600 ng/mL), and for Pregabline and Gabapentine was (100-4000ng/mL) and $\mathrm{r}^{2}>0.992$ for all analysts. A 440 urine samples have been analyzed using both immunoassay technique and LC/MS/MS by direct injection method giving a good comparison to illustrate how this method was specific, accurate, precise, and applicable for forensic urine samples.

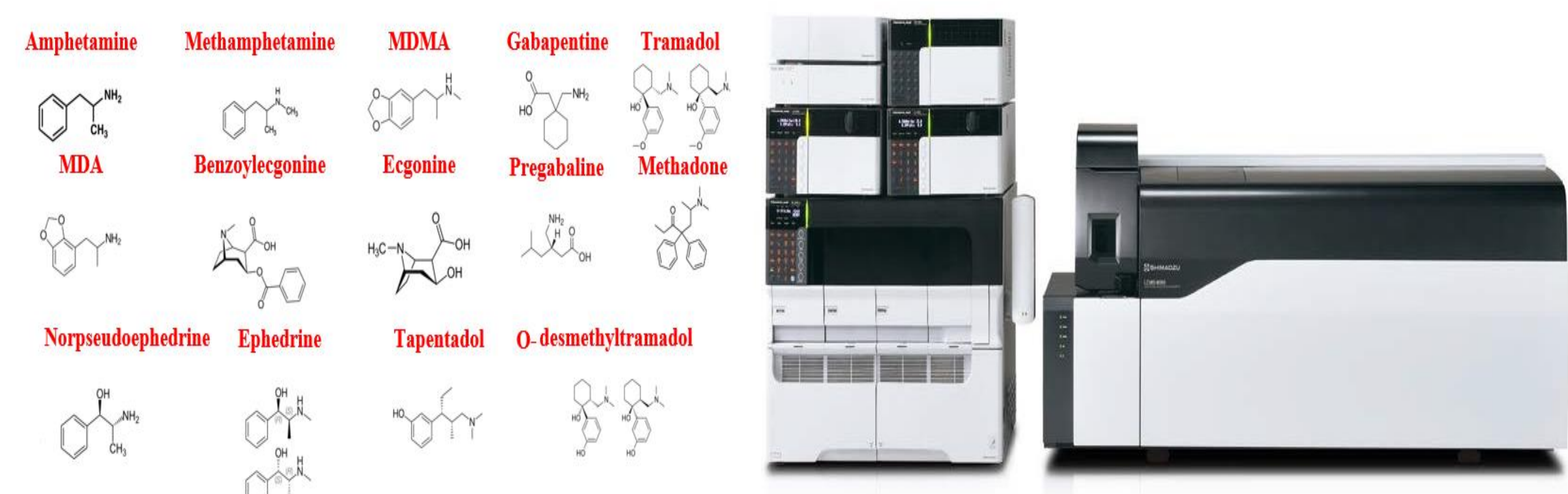

Fig. (1): Drugs Under Investigation and the LC/MS/MS Equipment

\section{LC/MS/MS Liquid Chromatography}

\section{Instrumentation and Conditions}

The analysis was performed using a Shimadzu 8050 LC-MS/MS triple quadruple mass spectrometer (Kyoto, Japan) coupled with a Shimadzu UHPLC Nexera X2 system (Kyoto, Japan). The mobile phase were used consists of $0.01 \mathrm{M}$ of ammonium acetate and $0.1 \%$ formic acid in water (A) and $0.01 \mathrm{M}$ of ammonium acetate and $0.1 \%$ formic acid in methanol with gradient mode.

\section{Immunoassay}

Two immunoassay instruments were used; (Abbott Archetict-4000c system, Waver, Belgium), and (V-Twin, Siemens). The kites were used are Pregabline, Amphetamines, Cocaine (Benzoylecgonine), Methadone and Tramadol at cut-off levels; 500, 300, 200, 200, $200 \mathrm{ng} / \mathrm{mL}$ respectively according to SAMHSA (5).

\section{Sample Preparation}

The very easy sample preparation were used, after the centrifugation and filtration of $0.5 \mu 1$ of urine sample by $0.2 \mu$ PPT filter, $50 \mu$ l of urine were diluted by $425 \mu 1$ of deionized water and $25 \mu \mathrm{l}$ of IS then $1 \mu \mathrm{l}$ was injected into LC/MS/MS.

\section{Method Validation}

The described method was validated in terms of linearity, limit of detection (LOD), limit of quantification (LOQ), specificity, stability, precision and accuracy according to international guidelines on the bioanalytical method validation.

\subsection{Linearity and quality control samples.}

Only deionized water was used to dilute the standard working solution. For calibration curve, $50 \mu \mathrm{L}$ from each level of standard working solutions were added to $425 \mathrm{~mL}$ of deionized water and $25 \mu \mathrm{L}$ of IS was added giving 10 fold diluted factor of the concentration levels of 50, 100, 200, 400, 800, 1200 and $1600 \mathrm{ng} / \mathrm{mL}$ for Tapentadol, Tramadol, Odesmethyltramadol, and Methadone, and 60, 150, 300, 600, 1200, 1800 and $2400 \mathrm{ng} / \mathrm{mL}$ for Amphetamine, Methamphetamine, MDMA, MDA, Benzoylecgonine, Norpseudoephedrine and Ephedrine and 100, 200, 500, 1000, 2000, 3000 and $4000 \mathrm{ng} / \mathrm{mL}$ for Pregabline and Gabapentine at concentration, then $1 \mu \mathrm{l}$ was injected into LC/MS/MS (Fig. 2). Quality control of analyses were prepared at 100, 200, $300 \mathrm{ng} / \mathrm{mL}$.

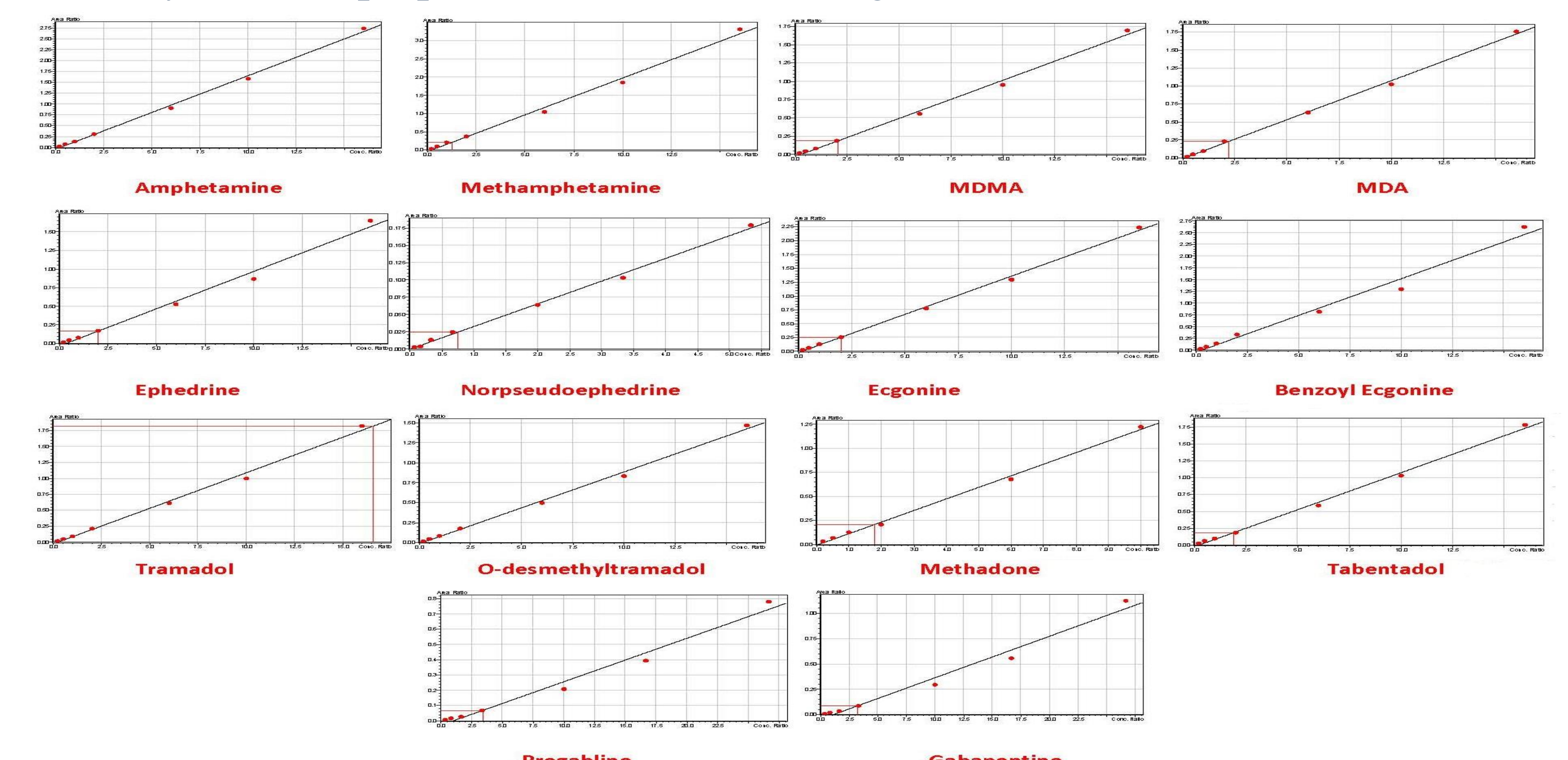

Fig. (2): Calibration Curves for the Investigated Fourteen Drug Compounds

\subsection{Selectivity (Specificity)}

Selectivity was studied by analyzing 10 different blank urine samples. No any interferences were observed at the retention time of the analyses and internal standards, (Fig. 3).
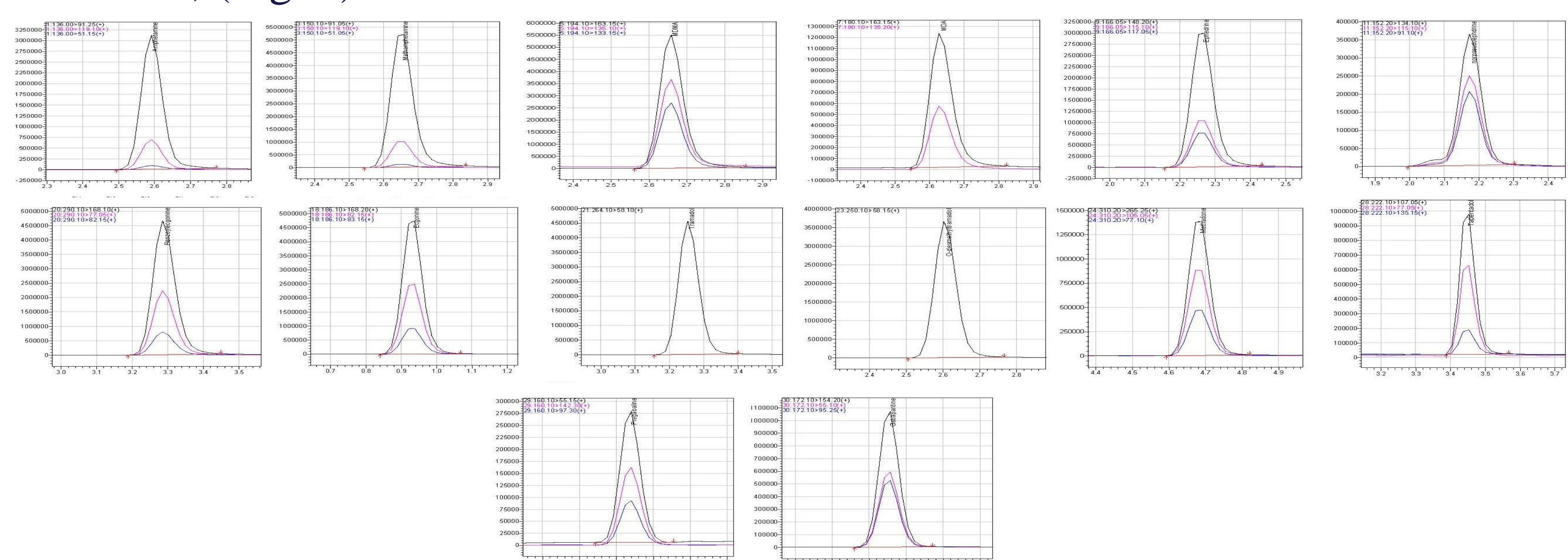

Fig. (3): Individual MRM chromatograms of 14 drugs at $300 \mathrm{ng} / \mathrm{mL}$ for each Amphetamine

\section{Results and Discussion}

A 440-urine sample were analyzed by the two-immunoassay techniques. A many false positive and false negative results were observed as in (Table 1). The results were confirmed by LC/MS/MS and GC/MS. About (14-20 \%) of Amphetamines tests were given false negative results by immunoassay technique, while (6-10\%) were given false positives, about of (17-20\%) of Pregabline tests were given false negative, while (5-6\%) were given false positive and about (15-30\%) of Tramadol, Benzoylecgonine and Methadone were given false negative results, while no false positive were detected of these analyses.

Table. (1): MRM Transitions, Retention Time Table. (2): False positive and false negative and Compound Tuning Parameters

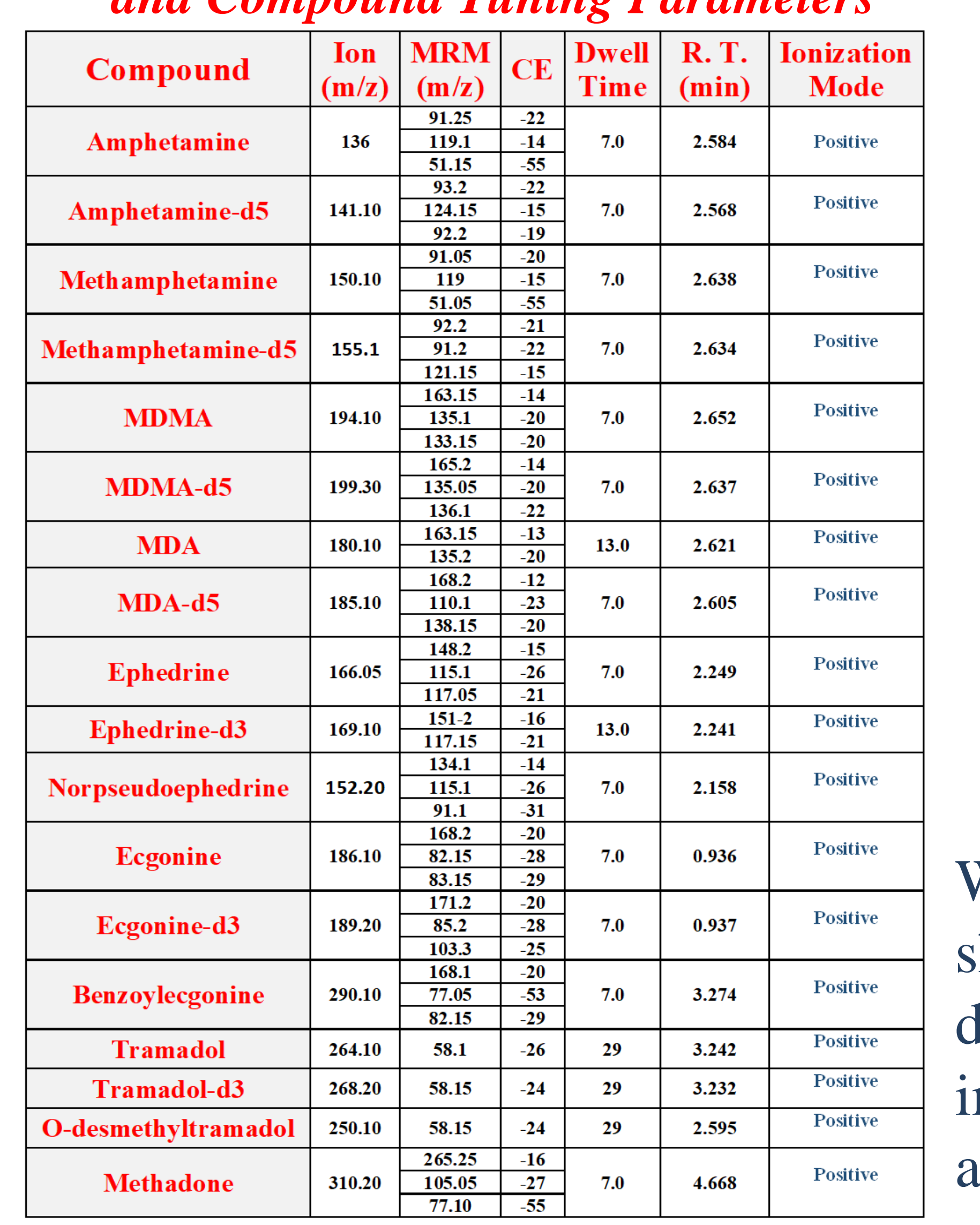
results of 440 urine samples

\begin{tabular}{|c|c|c|c|c|c|c|c|c|c|c|}
\hline \multirow[t]{2}{*}{ Tests } & \multicolumn{4}{|c|}{$\begin{array}{l}\text { Abbott Architect - } \\
4000 \mathrm{c}\end{array}$} & \multicolumn{4}{|c|}{ V-Twin-Siemens } & \multicolumn{2}{|c|}{$\begin{array}{c}\begin{array}{c}\text { Confirmed } \\
\text { Results }\end{array} \\
\end{array}$} \\
\hline & $\mid \begin{array}{c}\mathbf{F} \\
\text { tve }\end{array}$ & $\begin{array}{c}\text { F. } \\
-\mathrm{ve}\end{array}$ & Pos. & Neg. & $\begin{array}{l}\text { F. } \\
\text { +ve }\end{array}$ & $\begin{array}{c}\begin{array}{c}\text { F. } \\
-\mathrm{ve}\end{array} \\
\end{array}$ & Pos. & Neg. & Pos. & Neg. \\
\hline $\begin{array}{l}\text { Amphetamines } \\
\text { (cut-off } 300 \mathrm{ng} / \mathrm{mL} \text { ) }\end{array}$ & 32.0 & 25.0 & 98.0 & 285.0 & 18.0 & 21.0 & 122.0 & 299.0 & 123.0 & 377.0 \\
\hline $\begin{array}{c}\text { Cocaine } \\
\text { (cut-off } 200 \mathrm{ng} / \mathrm{mL} \text { ) }\end{array}$ & 0.0 & 3.0 & 6.0 & 431.0 & 0.0 & 3.0 & 6.0 & 431.0 & 9.0 & 431.1 \\
\hline $\begin{array}{c}\text { Tramadol } \\
\text { (cut-off } 200 \mathrm{ng} / \mathrm{mL} \text { ) }\end{array}$ & 2.0 & 6.0 & 32.0 & 400.0 & 2.0 & 6.0 & 32.0 & 400.0 & 38.0 & 422.0 \\
\hline $\begin{array}{c}\text { Methadone } \\
\text { (cutt-off } 200 \mathrm{ng}(\mathrm{mL})\end{array}$ & 0.0 & 4.0 & 13.0 & 423.0 & 0.0 & 4.0 & 13.0 & 423.0 & 17.0 & 423.0 \\
\hline $\begin{array}{c}\text { Pregabline } \\
\text { (cut-off } 500 \mathrm{ng} / \mathrm{mL} \text { ) }\end{array}$ & 19.0 & ${ }^{16.0}$ & 76.0 & 329.0 & 23.0 & 19.0 & 73.0 & 325.0 & 92.0 & 348.0 \\
\hline
\end{tabular}

While the false negative results, were shown in the low concentration samples due to the high cut-off limits of the immunoassay techniques. In forensic application, these issues should be avoided.

LC/MS/MS technique is the golden solution to avoid these failures of immunoassay technique. The false positive and false negative results were completely avoided in direct injection LC/MSMS method as in (Table 2). The method more specific, more accurate and more reliable than the immunoassay techniques.

\section{Conclusion}

High numbers of false positive and false negative results came during the analysis of 440 urine samples by immunoassay techniques in forensic applications. These false positive because the high of cross reactivity -low selectivity- with the compound structurally like amphetamine and Pregabline and also because of putrefaction in case of post-mortem cases. False negative results, mainly due to the high cut-off values of the immunoassay techniques. A simple, sensitive and specific LC/MS/MS direct injection method for determination of Amphetamine, Methamphetamine, MDMA, MDA, Benzoylecgonine, Norpseudoephedrine, Ephedrine, Tapentadol, Methadone, Tramadol, O-desmethyltramadol, Pregabline and Gabapentine in diluted urine samples in forensic application, was developed and validated according to the international guidelines. Use of LC/MS/MS as an alternative screen test, significantly decreased the numbers of false negative and false positive results in forensic toxicology analysis.

\section{References}

1. Katz, N., Fanciullo, G.J. (2002) Role of urine toxicology testing in the management of chronic opioid therapy. Clinical Journal of Pain, 18, S76-S82.

2. Lee MR, Song YS, Hwang BH, Chou CC. Determination of amphetamine and methamphetamine in serum via headspace derivatization solid-phase microextraction-gas chromatography-mass spectrometry. J Chramatogr A 2000; 896:265-73

3. Lee HH, Lee JF, Lin SY, Chen PH, Chen BH. Simultaneous determination of HFBA-derivatized amphetamines and ketamines in urine by gas chromatography-mass spectrometry. J Anal Toxico1 2011; 35;162-9.

4. Lachenmeier DW, Kroener L, Musshoff F, Madea B. Determination of cannabinoids in hemp food products by use of solid-phase microextraction headspace and gas chromatography-mass spectrometry. Anal Bioanal Chem 2004; 378:183-9.

5. Federal Register /Vol. 69, No. 71 /Tuesday, April 13, 2004 Mandatory Guidelines and Proposed Revisions to Mandatory Guidelines for Federal Workplace Drug Testing Programs; Notices Section 2.4 Laboratory Analysis Procedures (f) (1) confirmatory

6. R. Verplaetse, S. Decabooter1, E. Cuypers1 and J. Tytgat1 Screening of Urine and Blood Using Limite Sample Preparation and Information Dependent Acquisition with LC-MS/MS as Alternative for Immunoassays in Forensic Toxicology. J Forensic Toxicol Pharmacol 2013, 2:2 